PNNL-11060

UC-810

Project Technical Information

Determination of Halogen Content in Glass for Assessment of Melter Decontamination Factors

R. W. Goles
RECEIVED APR 011996

OSTI

March 1996

Prepared for

the U.S. Department of Energy under Contract DE-AC06-76RLO 1830

Pacific Northwest National Laboratory Richland, Washington 99352

* Battelle

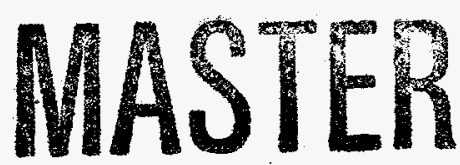



PNNL-11060

UC-810

Project Technical Information

\section{Determination of Halogen Content in Glass for Assessment of Melter Decontamination Factors}

R. W. Goles

March 1996

Prepared for

the U.S. Department of Energy

under Contract DE-AC06-76RLO 1830

Pacific Northwest National Laboratory

Richland, Washington 99352 


\title{
DISCLAIMER
}

This report was prepared as an account of work sponsored by an agency of the United States Covernment. Neither the United States Covernment nor any agency thereof, nor Battelle Memorial Institute, nor any of their employees, makes any warranty, express or implied, or assumes any legal liability or responsibility for the accuracy, complefeness, or. usefulness of any information, apparatus, product, or process disclosed, or represents that its use would not infringe privately owned rights. Reierence herein to any specific commercial product, process, or service by trade name, trademark, manuiacturer, or othenwise does not necessarily constitute or imply its endorsement, recommendation, or favoring by the United States Government or any agency thereof, or Battelle Memorial Institute. The views and opinions of authors expressed herein do nor necessarily state or reflect those of the United States Government or any agency thereof.

\author{
PACIFIC NORTHWEST NATIONAL LABORATORY \\ operated by \\ BATTELLE \\ for the \\ UNITED STATES DEPARTMENT OF ENERCY \\ under Contract DE-AC06-76RLO 1830
}

\author{
Printed in the United States of America \\ Available to DOE and DOE contractors from the \\ Office of Scientific and Technical Information, P.O. Box 62, Oak Ridge, TN 37831; \\ prices, available from (615) 576-8401.
}

Available to the public from the National Technical Information Service, U.S. Department of Commerce, 5285 Port Royal Rd., Springfieid, VA 22161 


\section{SUMMARY}

Melter decontamination factor (DF) values for the halogens (fluorine, chlorine, and iodine) are important to the Hanford Waste Vitrification Plant (HWVP) process because of the potential influence of DF on secondary waste recycle strategies (fluorine and chlorine) as well as its impact on off-gas emissions (iodine). This study directly establishes the concentrations of halides in HWVP simulated reference glasses rather than relying on indirect off-gas data. For fluorine and chlorine, pyrohydrolys is coupled with halide (ion chromatographic) detection has proven to be a useful analytical approach suitable for glass matrices, sensitive enough for the range of halogens encountered, and compatible with remote process support applications. Results obtained from pyrohydrolytic analysis of pilot-scale ceramic melter (PSCM) -22 and -23 glasses indicate that the processing behavior of fluorine and chlorine is quite variable even under similar processing conditions.

Specifically, PSCM-23 glass exhibited a $~ 90 \%$ halogen ( $F$ and $C 1$ ) retention efficiency, while only $20 \%$ was incorporated in PSCM-22 glass. These two sets of very dissimilar test results clearly do not form a sufficient basis for establishing design DF values for fluorine and chlorine. Iodine retention efficiency, established by $x$-ray fluorescence, could only be established for PSCM-22 glass, which exhibited an $8 \%$ loading. These halogen glass compositional results are found, moreover, to be in good overall agreement with off-gas derived values previously obtained.

Because the present data do not provide any new halogen volatility information, but instead reconfirm the validity of previously obtained offgas derived values, melter DF values of 4,2 , and 1 for fluorine, chlorine, and iodine, respectively, are recommended for adoption; these values were conservatively established by a team of responsible engineers at Westinghouse Hanford Company (WHC) and Pacific Northwest Laboratory (PNL) on the basis of average behavior for many comparable melter tests. In the absence of further HWVP process data, these average melter DFs are the best values currently available. 
The results of this study have validated the approach used to establish conservative baseline halogen DF values. From the performance values adopted and the results of the present study, halogen volatility will have a lesser secondary waste recycle effect (chlorine and fluorine) than earlier postulated. Similarly, the iodine OF value of 1 is consistent with earlier assumed values, and no change in off-gas radiological requirements is needed based on this study. 


\section{GLOSSARY OF ACRONYMS}

DF

DWPF

HLLW

HWVP

IC

ICP

ISE

LFCM

MS

PNL

PSCM

WHC

WVDP decontamination factor (rate in $\div$ rate out)

Defense Waste Processing Facility

high-level liquid waste.

Hanford Waste Vitrification Plant

ion chromatography

inductively coupled plasma

ion selective electrode

liquid-fed ceramic melter

mass spectrometry

Pacific Northwest Laboratory

pilot-scale ceramic melter

Westinghouse Hanford Company

West. Valley Demonstration Project 



\section{CONTENTS}

SUMMARY ................................ i ...

GLOSSARY OF ACRONYMS .......................... . . . v v

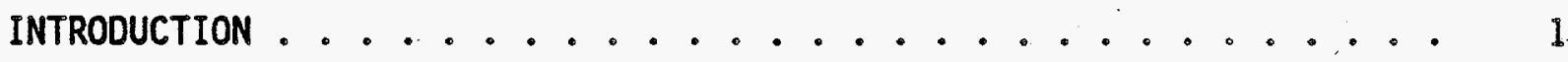

HALOGEN ANALYSIS . . . . . . . . . . . . . . . . . . 5

PYROHYDROLYTIC-ION CHROMATOGRAPHIC ANALYSIS . . . . . . . . 9

$X$-RAY FLUORESCENCE ANALYSIS . . . . . . . . . . . . 9

ANALYTICAL RESULTS ........................ 11

CONCLUSIONS ... . . . . . . . . . . . . . . . 15

REFERENCES ........................... 17 


\section{INTRODUCTION}

The Hanford Waste Vitrification Plant (HWVP) is being designed to use iiquid-fed ceramic melter (LFCM) technology to vitrify the pretreated highlevel liquid defense wastes (HLLW) currently being stored in underground tanks on the Department of Energy's Hanford Site in southeastern Washington. Joule-heated, ceramic-lined melters form the basis of the LFCM process, which is schematically illustrated in Figure 1. This type of gilass melter,

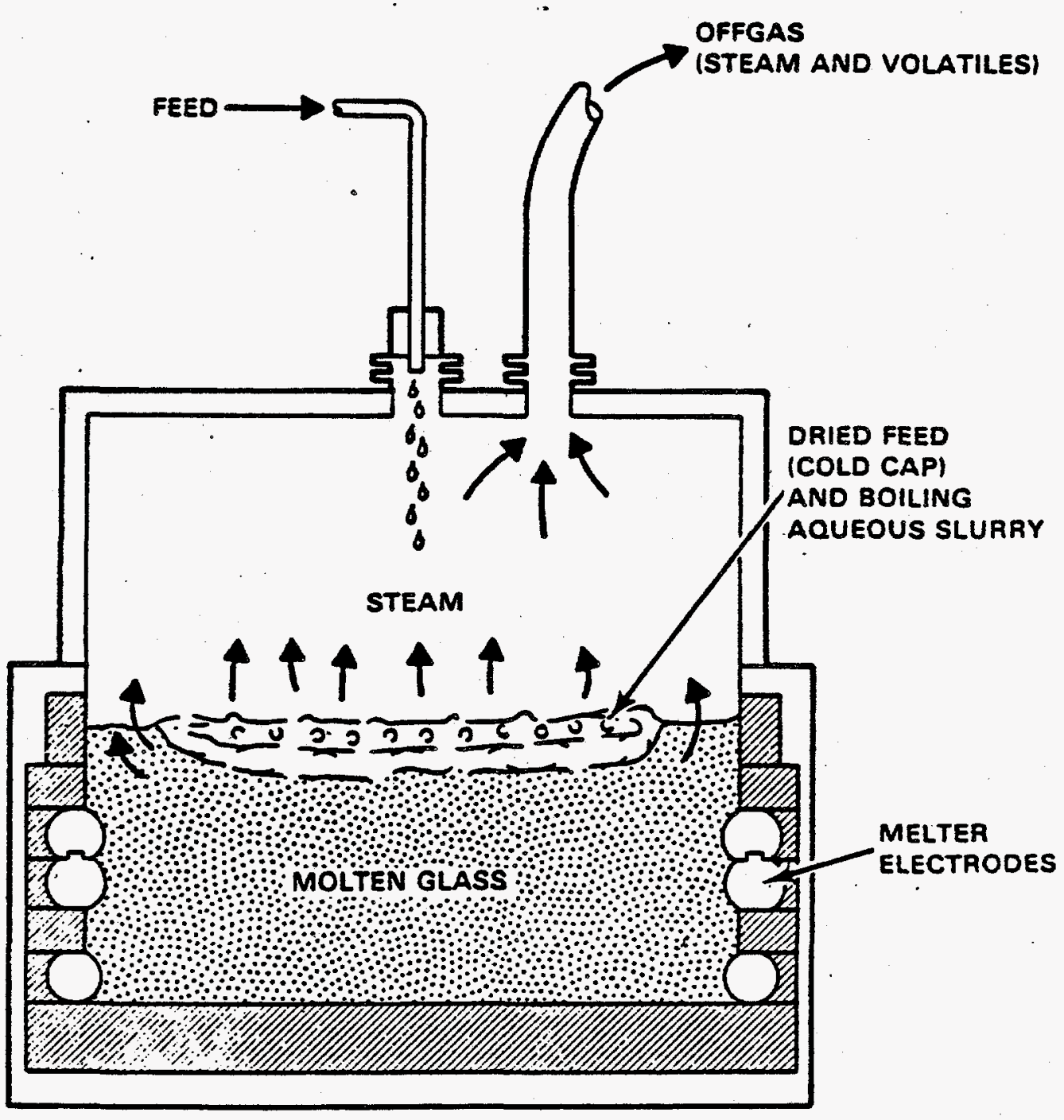

FIGURE 1. Schematic Illustrating the LFCM Process 
developed for the commercial glass industry, is composed of a heavily insulated, ceramic-lined cavity, which contains the molten glass, and corrosion-resistant electrodes. The power required to maintain the glass in its molten state and to process feed chemicals is supplied by electrical resistive heating produced by passing an electric (AC) current through the glass pool via the immersed melter electrodes; this is known as Joule heating. Because Joule-heated ceramic melters can attain higher temperatures than conventional melters, high-silica glasses with exceptional chemical stability can be fabricated using this device. This is an important feature in LFCM applications, as the vitreous waste form must exhibit low aqueous leaching rates to qualify for long-term geologic storage.

Application of Joule-heated ceramic melters to the vitrification of HLLW is a straightforward extension of glass-making technology; the waste components are treated as a subset of the chemicals needed to produce a specific glass product. In the LFCM process, major glass-forming chemicals and/or glass frit are mixed with the HLLW stream to produce an aqueous slurry that is continuously fed to the Joule-heated melter, where it is dried, calcined, and melted to produce a molten radioactive glass that commoniy has a waste loading of 25 wt\%. The molten glass product is then transferred, via an overflow port, to metal canisters that are subsequentiy cooled and sealed to further isolate the immobilized waste form.

Under ideal circumstances, all waste and glass-forming components of the slurry feed would be totally incorporated into the LFCM glass product and the process exhaust would be composed only of steam. In fact, however, significant effluent losses are found to accompany LFCM processing (Goles and Sevigny 1983). Due to the turbulence of the evaporation and calcination processes, aerosol emission is responsible for most slurry component losses (DF $\geq 500$ ); however, the high processing temperatures $\left(1050^{\circ} \mathrm{C}\right.$ ) also promote high volatility loss rates (DF < 10) for a few slurry components (Goles, Mishima, and Schmidt 1989). Even minor feed components can have a major influence on off-gas waste stream composition and on subsequent recycle strategies, if these components can be volatilized or otherwise form gaseous compounds. Under total recycle conditions, the concentration of melter feed components can increase unacceptably if they are highly volatile. Volatility 
can also result in undesirable waste processing corrosion problems. For this reason, the volatile halogens--fluorine, chlorine and iodine--are of primary importance.

The halide content of melter feed can also influence the LFCM process by affecting melter performance. A significant body of evidence suggests that the halogen content of the melter feed will influence melter DFs for the alkali elements, of which ${ }^{137} \mathrm{Cs}$ is a very important member (Goles and Andersen 1986). If off-gas system liquid waste streams are recycled to the melter feed preparation vessels, the halogen content will increase and melter cesium DFs could decrease significantly. This behavior is based on the melter glass having a fixed maximum halogen capacity (Volf 1984; Bates 1987). Because the halides of many other feed components are volatile at LFCM operating temperatures, increasing the halide content of the melter feed stream could also serve to decrease melter vitrification efficiency by increasing the importance of melter volatility losses to the overall melter source term. Given the potential synergistic effects of the halogens upon melter performance, the processing behavior of the halogens will be a very important factor in establishing the overall HWVP waste processing flow sheet.

Unlike fluorine and chlorine, iodine is not a significant chemical component in reference HWVP waste, and because of its unique chemistry, it will not accumulate to any extent in aqueous secondary waste streams (Burger and Scheele 1989). As a result, melter processing behavior of iodine will have no significant influence upon the HWV process flow sheet or recycle strategy options, although it will impact the plant's radiological source term. This study will, therefore, be primarily concerned with the processing characteristics of chlorine and fluorine, and the term "halogen" will henceforth be used to refer only to these two elements unless otherwise noted. The processability of iodine as it relates to off-gas design issues will be discussed separately.

Current knowledge about the nature and magnitude of melter off-gas system losses of the halogens has been derived almost exclusively from offgas system samples extracted during pilot-scale ceramic melter (PSCM) simulation tests of the LFCM and its associated off-gas treatment systems. 
The Pacific Northwest Laboratory (PNL)(a) has conducted cold melter tests in support of Savannah River's Defense Waste Processing Facility (DWPF), the West Valley Demonstration Project (WVDP), and the HWVP; in all cases, melter DFs for chlorine have been consistently observed to be $<<10$, but within that limit they have also varied considerably. For the HWVP tests, chlorine melter DFs have ranged from 6.6 to 1.3 ; corresponding fluorine DFs have varied from 9.2 to 3.2. Although the test-to-test variability of halogen DFs is significant, the results obtained throughout the duration of a given test are quite reproducible. These observations suggest either that cold cap halogen chemistry is a strong feed compositional variable or that the sampling and/or analysis data may be somehow biased and nonrepresentative. To resolve this issue and obtain average melter halogen DFs without incurring the potential biasing influences of the off-gas system, the halogen content of the glass product must be directly measured. This has been accomplished for HWVP simulated glasses, as will be described in this report.

The specific objectives of this report (IVJ0020500D), as defined by the Letter of Instruction from Westinghouse Hanford Company (WHC) and PNL's FY 1989 Work Plan, are as follows:

- Develop analytical techniques for determining the halogen content in LFCM glasses and off-gas samples.

- Establish melter OFs for halogens in glasses produced during PSCM-22 and PSCM-23 melter tests.

- Recommend halogen DFs for the HWVP melter and off-gas system components.

This report will first describe halogen analytical methodologies and the techniques developed to analyze LFCM samples. The results of using these techniques on PSCM-22 and $-23 \mathrm{glass}$ samples will be discussed and the resultant halogen DF data will be compared to calculated values based on offgas sampling data. The report will conclude by recommending halogen DF values for the HWVP melter and off-gas system components.

(a) Operated for the U.S. Department of Energy by Battelle Memorial Institute under Contract DE-AC06-76RLO 1830. 


\section{HALOGEN ANALYSIS}

The most direct approach for establishing average melter halogen DFs is to determine the halogen composition of the feed stream and the glass. Al though feed stream analysis has been accomplished using conventional chemical manipulations and ion chromatographic (IC) and/or ion selective electrode (ISE) detection (potentiometric) approaches, meaningful glass analyses using similar approaches have not been possible because of the extreme conditions required to dissolve the glass matrix.

Dissolution of glass, called fusion, is a high-temperature process that can cause losses in halogen volatility (Tominaga et al. 1979) and results in very high-ionic-strength solutions that must be greatiy diluted before detection can take $p l a c e$. In the cases where these high required dilutions have not reduced halogen concentrations below their detection limits, the combination of volatility losses and chemical contamination of the sample by the fusion flux has produced highly variable halogen glass compositional data. These analytical 1 imitations result in inherently imprecise glass compositional data for trace components. This is precisely why off-gas sampling data have been used to estimate halogen melter DFs.

In an effort to provide a direct and more reliable analytical method for establishing melter halogen DFs, a literature search was conducted to identify alternative halogen analytical approaches that have been successfully applied to geologic and/or siliceous (silica-containing) materials that would be

- suitable for glass matrices

- sensitive enough for the range of melter DFs observed

- practical for remote applications.

Remote applicability of the analytical approach is not completely necessary, as there is no specific requirement for this type of analysis on process glasses. However, compatibility of the analytical approach with remote radioactive environments could be quite advantageous if there is future need to evaluate the halogen content of bench-scale radioactive test glasses. 
Analytical approaches for fluorine determinations are most often found to involve basic fusion or acid digestive (Edmond 1969) processes, which are used to prepare the sample for ultimate analysis using spectrophotometry (Gimeno Adelantado et a1. 1985; Leon-Gonzalez et a1. 1985) or ISE detection (Thomas and Gluskoter. 1974; Bodkin 1977). These methods, as noted above, can be applied only with extreme difficulty to glass matrices in controlled laboratory environments and are clearly not applicable to remote environments. Other techniques that have been successfully used to eliminate chemical interferences and analytical biases due to sample preparation (Edmond 1969; Leon-Gonzalez et al. 1985) include 1) neutron and photon activational analyses (Tominaga et al. 1979; Reed 1968) which, because of their need for specialized irradiation facilities, are clearly not compatible with process support applications, and 2) pyrohydrolytic-based analytical approaches which, because of their simplicity and sensitivity, have been found to be quite suitable for remote applications.

Hydropyrolysis (or pyrohydrolysis) is an effective high-temperature method for selectively releasing fluorine and chlorine from silicate rocks as hydrogen halides (Conrad and Brownlee 1988; Hall, MacLaurin, and Vaive 1986; Whitehead and Thomas 1985; Evans and Moore 1980; Evans, Tarter, and Moore 1981). The hydrogen halide released by this process is usualiy quantitatively captured by an aqueous medium, whereupon the halide is analyzed, interference free, by spectrophotometry (CI), IC ( $F$ and $C 1$ ), and/or ISE potentiometry ( $F)$. The analytical sensitivity associated with hydropyrolytic-based techniques is more than sufficient to establish the halogen content of HWVP reference glasses. In particular, the pyrohydrolytic-IC analytical approach is capable of detecting halogens at 20 -ppm levels in a 100 -mg sample with a $\pm 5 \%$ relative standard deviation (Ha11, MacLaurin, and Vaive 1986).

The analytical techniques most often used to detect chlorine in geologic materials are neutron activation (Johansen and Steinnes 1967), $x$-ray fluorescence ( $F a b b i$ and Espos 1972), spectrophotometry or IC of fused solutions (Huang and Johns 1967), and the hydropyrolytic separation and detection methods previously discussed. Of these methods, neutron activation, although extremely sensitive, is not a practical process support tool 
because it requires specialized irradiation facilities. $X$-ray fluorescence, although useful for all halogens except fluorine, can only be effectively used for the analysis of nonradioactive samples and, consequently, is of little value for process support. Fusion and pyrohydrolytic-based chlorine detection methods exhibit the same analytical liabilities and advantages, respectively, as do the corresponding fluorine techniques. Thus, as for fluorine, the pyrohydrolytic technique is the only analytical method for vitreous chlorine that is compatible with both sensitivity and process support requirements of the HWVP.

Mass spectrometry (MS) is an analytical tool that could be used to support the general analytical requirements of the HWVP. The technique is compatible with most elements, major and minor, but, because of the nonreproducibility of conventional ion sources, it lacks the necessary precision for conducting quantitative comparisons (Reed 1968). A spark source mass spectrometer was used to demonstrate these facts for HWVP glasses. The approach was fully capable of identifying the presence of halogens in these reference glasses, but could only estimate their concentrations to within a factor of three uncertainty, which is at best only a semiquantitative result.

The development of the glow discharge ion source has significantly improved the prospects for using mass spectrometry directly for analytical process control. It has been estimated that halogen determinations in a glass matrix could be directly determined by glow discharge mass spectrometry to $\pm 10 \%$ uncertainty, provided that matrix matched standards are available. (a) The influence of matrix composition upon instrumental accuracy is a major limitation of this analytical approach, as adequate glass standards are not available.

Inductively coupled plasma (ICP) ionization sources have also extended the utility of mass spectrometers; however, ICP-MS is not directly applicable to solid samples, and therefore could only be used as a detection device in much the same way that IC or ISE methods are used to support fusion and/or pyrohydrolysis analytical approaches. Under these conditions, ICP-MS cannot

(a) R. Guidoboni, Northern Analytical, Amherst, New Hampshire, personal communication. 
support fluorine detection because of mass 19 interference from the $\mathrm{OH}$ radical. Neither glow discharge nor ICP-MS has been applied to the analysis of halogens in geologic and/or siliceous materials, although there is no fundamental reason why they could not be.

To summarize the above findings, hydropyrolytic separation of fluorine and chlorine, coupled with an appropriate detection method, is the only analytical approach compatible with the matrix and sensitivity limitations imposed by HWVP glasses and suitable for process applications. Spectrophotometry, ISE, and IC have all been used successfully with pyrohydrolysis for the detection of fluorine, chlorine, and fluorine and chlorine, respectively. ICP-MS could also be an effective pyrohydrolytic chlorine detection device; however, this capability has not yet been developed either at PNL or at the DWPF. (a) Glow discharge mass spectrometry has the potential to be a standalone glass compositional analytical tool, but its capabilities are completely undeveloped in this particular area and adequate standards do not exist. All of these findings were verified through discussions with independent analytical contract laboratories, (b) national and government laboratories, (c) and universities. (d)

Because of the need to use proven analytical methods to determine melter halogen DFs, the pyrohydrolytic-IC method-has been chosen to establish glass composition data for fluorine and chlorine. Chlorine glass composition will also be independently measured using $x$-ray fluorescence techniques, which will provide iodine data as well. However, iodine was present only in the PSCM-22 feed stream. The analytical procedures used are discussed below. The results obtained from these analyses are presented in the following section.

(a) M. J. Plodinec, Savannah River Laboratory, Aiken, SC:

(b) Corning Glass Works, Corning, NY; Wyoming Analytical Laboratory, Boulder, CO; General Electric, Valicetos Operations, Sunol, CA; Northern Analytical, Amherst, NH; General Activation Analysis, Los Angeles, CA.

(c) Savannah River Laboratory, Aiken, SC; Idaho National Engineering Laboratory, Idaho Falls, ID; West Valley Nuclear Services, West Valley, NY; National Institute of Standards and Technology, Gaithersburg, MD.

(d) Chemistry Department, University of Cincinnati, Cincinnati, OH; Chemistry Department, University of California, Irvine, CA. 
PYROHYDROLYTIC-ION CHROMATOGRAPHIC ANALYSIS

The pyrohydrolytic extraction apparatus used in the present study is illustrated in Figure 2. The ceramic combustion tube and all sample boats were subjected to experimental conditions of $1200^{\circ} \mathrm{C}$, an argon purge rate of $0.5 \mathrm{~T} / \mathrm{min}$, and a water injection rate of $1.5 \mathrm{ml} / \mathrm{min}$ until the halogen content in the alkaline gas scrubber solution stabilized at very low levels. Approximately $200 \mathrm{mg}$ of a powdered 100 mesh glass sample is then weighed into a ceramic sample boat that is subsequently placed in the middle of the heated combustion tube. The argon-steam purge, which is initiated immediately after sample boat introduction, quantitatively extracts and sweeps the volatilized halogens into an aqueous quencher/scrubber, where they are efficiently collected over a 10-minute period. Blanks and geologic standards are also processed under identical sample collection conditions. All resultant halide solutions--blank, sample and standard--were analyzed using standard IC procedures. The complete pyrohydrolytic procedure used to extract halogens from glass is included as appendix to this report.

\section{$\underline{X-R A Y ~ F L U O R E S C E N C E ~ A N A L Y S I S ~}$}

A commercial, Kevex Model 0810A energy-dispersive $x$-ray fluorescence analysis system was used to analyze the chlorine content of HWVP simulated glasses. The computer-controlled system uses recursive data reduction methods that eliminate the need for matrix matching. As a result, this technique has been applied successfully to a wide variety of sample types including geologic, glass, biologic, and metallic matrices. The only sample preparation required for optimal detection sensitivity is the reduction of the sample to a -300 mesh powder, which is pressed into a thin, uniform (13 in. diameter) target for subsequent irradiation and analysis. Titanium and zirconium targets were used to stimulate chlorine $x$-ray emissions; a gadolinium excitation source was used for iodine. Since $x$-ray fluorescence is almost a totally instrumental analysis technique, there is very little risk of sample contamination; this is one of the technique's greatest advantages. However, $x$-ray fluorescence detection sensitivities may not be as high as those of other analytical techniques. 


\section{ANALYTICAL RESULTS}

Archived glass samples (HW-39) from PSCM-22 and PSCM-23 melter tests were exclusively used for this evaluation. The operating and processing conditions of these tests were quite similar. Each test was conducted for 18 days with greater than 95\% on-time efficiency, during which time a simulated HWVP feed consisting of pretreated neutralized current acid waste (NCAW) and premade glass-forming frit was processed. The waste oxide loading of PSCM-23 feed was $125 \mathrm{~g} / 1,25 \%$ higher than in PSCM-22. The method of feed preparation was the most significant difference between the feed streams used in these consecutive melter tests. The PSCM-23 feed was prepared to closely simulate the plant's flow sheet by precipitating major feed and waste components from nitrate solutions, rather than by using commercially available hydroxides as was done during PSCM-22. Because $\mathrm{NO}_{3}$ - concentrations were higher than expected $(35 \mathrm{~g} / 1)$, PSCM-23 also used approximately twice as much formic acid feed reductant $(23 \mathrm{~g} / 1)$ as was employed in PSCM-22. However, both tests produced glasses with comparable oxidation states.

Although the above differences would not be expected to significantly affect melter behavior, PSCM-23 feed was definitely more processable. Even though glass production rates were similar for the two tests, higher processing stability (with a smaller cold cap) and higher DFs were achieved during PSCM-23 than during the previous HWVP melter test. This is the only major distinction that could be drawn between. these very similar tests, but. it may an important one, as processability can be a function of cold cap chemistry.

Halogen compositional results obtained from the reference glasses produced during PSCM-22 and PSCM-23 melter simulation tests are summarized in Table 1. The weight percentages of the halogens are presented in this table along with the process efficiency for incorporating the halogens into the glass matrix, which is designated by \%Eff. Clearly, the halogen contents of the two sets of glasses are significantly different. This result supports previous conclusions based on off-gas sampling data. Table 2 compares average glass- and off-gas-based halogen data in terms of process efficiency and, equivalently, DF. The agreement between these two sets of independent 
data is remarkably good. All the chlorine and the PSCM-23 fluorine data listed in this table agree to within the analytical uncertainties listed in Table 1. The variance between PSCM-22 glass and off-gas data for fluorine and iodine is almost certainly due to the difficulties associated with quantifying these halogens in the insoluble off-gas sample matter; this finding confirms the need for the analytical alternatives that are being sought by this study.

TABLE 1. Composition and Percentage Incorporation of Halogens in HWVP GIasses

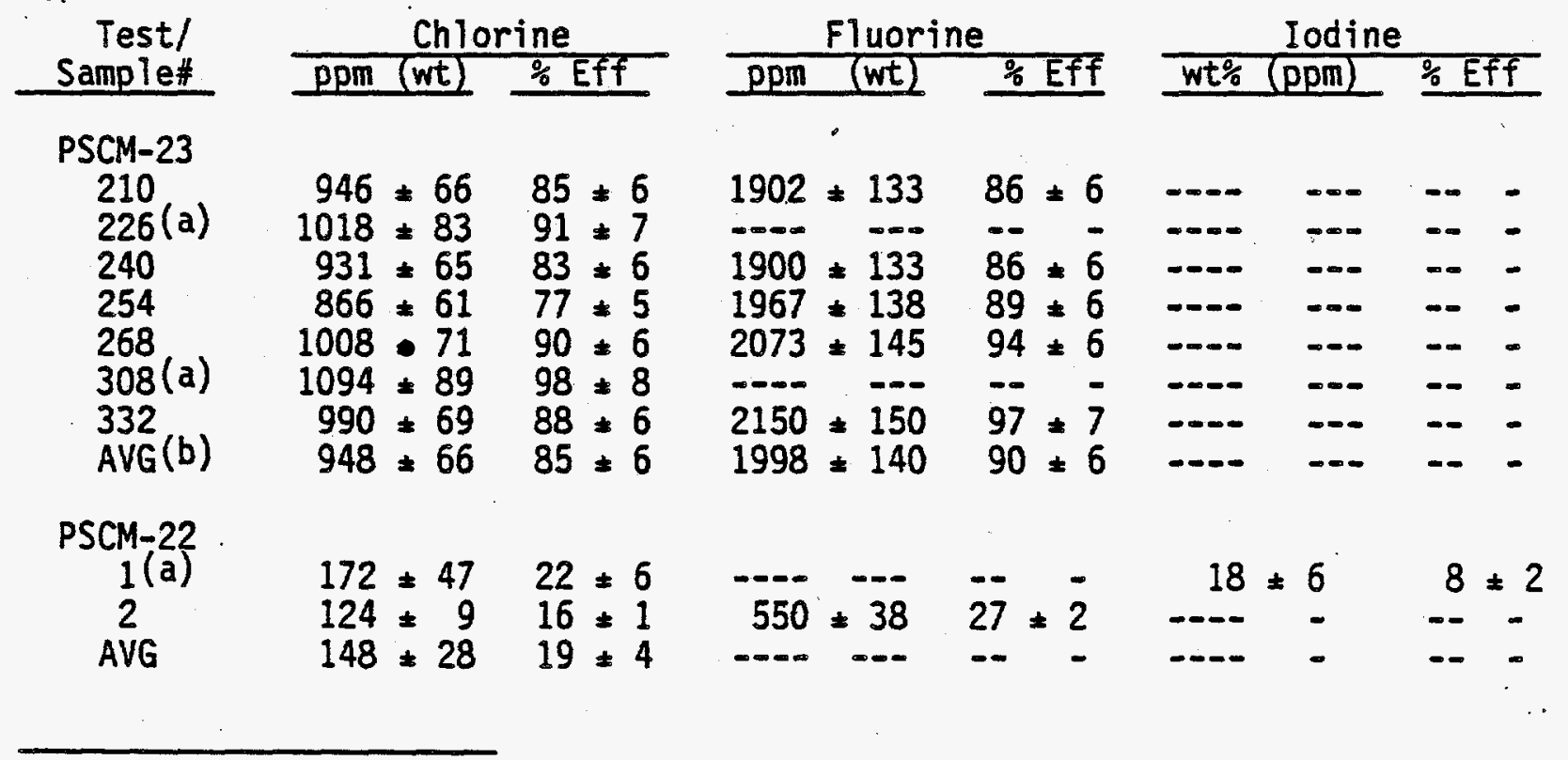

(a) Analyzed by $x$-ray fluorescence.

(b) X-ray data excluded from averaging.

The data in Tables 1 and 2 clearly show that halogen LFCM processing behavior can be quite variable. The specific reasons for this have yet to be identified, but the basis for the observed variability is definitely linked to differences in cold chemistry, as volatility dominates halogen melter losses (Goles et al. 1989). Although PSCM-23 is the most prototypic of the HWVP simulation tests, the high processing efficiencies that distinguished it cannot, at this point, be considered representative, as they are in marked contrast to PSCM-22 and most other melter test data. Because of this, conservative melter design DFs for the HWVP were derived from average 
TABLE 2. Comparison of Off-Gas and Glass Compositional Halogen Data

\begin{tabular}{|c|c|c|c|c|c|c|c|c|c|c|}
\hline \multirow[b]{2}{*}{ Test } & \multicolumn{4}{|c|}{ Chlorine } & \multicolumn{4}{|c|}{ Fluorine } & \multicolumn{2}{|c|}{ Iodine } \\
\hline & $\frac{\overline{\text { Off }}}{\frac{\text { gEff }}{b f^{\prime}}}$ & & $\frac{G}{\frac{G}{\partial E f}}$ & $\frac{5 S}{D F}$ & 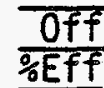 & $\frac{\text { GaS }}{D F}$ & $\frac{G}{\frac{G}{\partial E f}}$ & DF & $\frac{\overline{O f f-G a S}}{\frac{0 \mathrm{Off} D F}{D E}}$ & $\frac{\text { Glass }}{\text { offf DF }}$ \\
\hline$c \Omega$ & 85 & 6.6 & 85 & 6.5 & 89 & 9.2 & 90 & 10 & $-\infty$ & --- \\
\hline $\mathrm{CM}-$ & 23 & 1.3 & 19 & 1.2 & 69 & 3.2 & 27 & 1.4 & 1.3 & 8 \\
\hline
\end{tabular}

processing conditions of many similar melter test (Goles et al. 1989). This was especially appropriate for the halogens, as their volatility losses have been shown by this study to be quite variable. Because the results of the present study have added credibility to the approach used in making these assignments, and because no additional data have become available since that time, no rationale exists for changing the melter halogen DFs assignments made: 4, 2, and 1 for fluorine, chlorine, and iodine, respectively (Goles et al. 1989).

In the absence of more HWVP. off-gas data, these average performance OFs are the best values currently available. Additional LFCM testing will provide more prototypic data upon which refinements to the reference halogen DFs can be based. The analytical methods developed in this study will definitely improve the accuracy and verifiability of the halogen data to be collected. 


\section{CONCLUSIONS}

This study has evaluated analytical methods for directly establishing the processing behavior of chlorine and fluorine feed components by analyzing the halogen composition of the LFCM glass product. The pyrohydrolytic halide separation/detection method was the only demonstrated halogen analytical approach identified that was suitable for glass matrices, sensitive enough for the range of melter DFs observed, and compatible with remote process support applications. This technique was successfully applied to a series of simulated HWVP glasses produced and collected during PSCM-22 and PSCM-23 melter tests. Ion chromatography was used to simultaneously detect the chloride and fluoride ions in the aqueous scrub solutions that were used to capture the pyrohydrolytically released hydrogen halides. The results obtained were quite reproducible, as evidenced by the fact that the data obtained from a series of similar glasses (PSCM-23) exhibited a variance (standard deviation) that was less than half that of the analytical detection uncertainty. The processing behavior of iodine, which was only present in the PSCM-22 feed stream, was determined using the $x$-ray fluorescence chlorine verification technique.

Spectrophotometric, potentiometric (ISE), and, possibly; mass spectrometric (ICP-MS) detection methods can also be effectively combined with pyrohydrolys is to quantify chloride, fluoride, and chloride and fluoride, respectively. Glow discharge mass spectrometry is an analytical alternative to pyrohydrolysis that offers the potential to directly determine glass composition with minimal sample preparation. Although analytically precise and compatible with glass-like sample materials, glow discharge mass spectrometry has not as yet been applied to halogen analysis in geologic and/or siliceous materials; thus, its capabilities in this application are totally unproven.

The results obtained from applying the pyrohydrolytic-IC analytical method to HWVP glasses reconfirmed the results obtained from off-gas sampling data. The halogen contents of PSCM-22 and PSCM-23 glasses were found to be significantly different, indicating that the processing behavior of the halogens is quite variable even under similar testing conditions. Although the PSCM-23 feed stream was the most prototypic of the simulated HWV melter 
tests, it is inappropriate to establish reference melter performance values on the basis of a single test, as reproducibility has not been established. Melter DF values of 4, 2, and 1 for fluorine, chlorine, and iodine, respectively, are therefore recommended for adoption, as these values were conservatively established by a team of responsible WHC and PNL engineers on the basis of average behavior for many melter tests (Goles et al. 1989).

The results of this study have validated the basis used for establishing baseline halogen DF values; moreover, these adopted DF values appear to be very conservative relative to PSCM-23 test data. From the adopted DF values confirmed in this report, it appears that recycle off-gas system waste will have a significantly lower halogen content than that estimated using early assumed halogen DF values which were on the order of 1 . This is expected to have a significant positive impact on waste recycle equipment corrosion and volatility of melter constituents. At the same time, the iodine DF value of 1 is consistent with earlier assumptions and is not expected to impact current reference radiological values associated with the off-gas treatment system. 


\section{REFERENCES}

Bodkin, J. B. 1977. "Determination of Fluorine in Silicates by Use of an Ion-Selective Electrode Following Fusion with Lithium Metaborate." Analyst 102:409-413.

Bates, S. 0. 1987. "FY 87 Glass Variability Testing Conducted for the HWVP." HWVP-87-V110202C, prepared for Westinghouse Hanford Company by the Pacific Northwest Laboratory, Richland, Washington.

Burger, L. L., and R. D. Scheele. 1989. HWVP Iodine Trap Evaluation. Prepared for Westinghouse Hanford Company by the Pacific Northwest Laboratory, Richland, Washington.

Conrad, V. B., and W. D. Brownlee. 1988. "Hydropyrolytic-Ion Chromatographic Determination of Fluoride in Coal and Geological Materials." Anal. Chem. $60: 365-369$.

Edmond, C. R. 1969. "Direct Determination of Fluoride in Phosphate Rock Samples Using the Specific Ion Electrode." Anal. Chem. 41:1327-1328.

Evans, L. E.:, and C. B. Moore. 1980. "Combustion-Ion Chromatographic Determination of Chlorine in Rocks." Anal. Chem. 52:1908-1912.

Evans, L. E., J. E. Tarter, and C. B. Moore. 1981. "Pyrohydrolytic-Ion Chromatographic Determination of Fluorine, Chlorine, and Sulphur in Geological Samples." Anal. Chem. 53:925-928.

Fabbi, B. P., and L. F. Espos. 1972. "X-Ray Fluorescence Determination of Chlorine in Standard Silicate Rocks." Appl. Spectrose. 26-2:293-295.

Gimeno Adelantado, J. V., et al. 1985. "Spectrophotometric Determination of Fluoride in Fluoride-Bearing Minerals After Decomposition by Fusion with Sodium Hydroxide." Talanta 32:224-226.

Goles, R. W., and G. J. Sevigny. 1983. "Off-Gas Characteristics of Liquid-Fed Joule-Heated Ceramic Melters." Proceedings of the 17th DOE Nuclear Air Cleaning Conference (1982: Denver, Colorado). National Technical Information Service, Springfield, Virginia.

Goles, R. W., and C. M. Andersen. 1986. "LFCM Emission and Off-Gas System Performance for Feed Component Cesium." In: Proceedings of the American Nuclear Society International Topical Meeting Waste Management and Decontamination and Decommissioning, September 14-18, 1986. Eds. Dr. J, M. Pope, I. M. Leonard, and E. J. Mayer. Niagara Falls, New York.

Goles, R. W., J. Mishima, and A. J. Schmidt. 1989. Evaluation of LFCM OffGas System Technologies and Atmospheric Emission Projections for the HWVP. HWVP-89-IVR0010201B, prepared for Westinghouse Hanford Company by the Pacific Northwest Laboratory, Richland, Washington. 
Goles, R. W., et a7. 1989. Hanford Waste Vitrification Program Pilot-Scale Ceramic Melter Test 23. HWVP-89-IVJ0010100B, prepared for Westinghouse Hanford Company by the Pacific Northwest Laboratory, Richland, Washington.

Ha11, G. E. M., A. I. MacLaurin, and J. Vaive. 1986. "The Analysis of. Geological Materials for Fluorine, Chlorine and Sulphur Using Pyrohydrolysis and Ion Chromatography." J. of Geochem. Expl. 26:177-186.

Huang, W. H., and W. D. Johns. 1967. "Simultaneous Determination of Fluorine and Chlorine in Silicate Rocks by a Rapid Spectrophotometric Method." Anal. Chim. Acta 37:508-515.

Johansen, 0., and E. Steinnes. 1967. Geochim. Cosmochim. Acta 31:11071109 .

Leon-Gonzalez, M. E., et al. 1985. "An Improved Method for the Spectrophotometric Determination of Fluoride by Addition of Sodium Dodecyl Sulphate to the Fluoride/Lantanum (III)/ATizarin Fluorine Blue System." Anal. Chim. Acta 178:331-335.

Reed, R. I., ed. 1968. Modern Aspects of Mass Spectrometry. Plenum Press, New York.

Thomas, J., Jr., and J. H. Gluskoter. 1974. "Determination of Fluoride in Coal with the Fiuoride Ion-Selective Electrode." J. Anal. Chem. 46:1321-1323.

Tominaga, $H_{.}$, et a7. 1979. "Determination of Fluorine in $\mathrm{Glasses}$ by Cyclic Activation Analysis Using a Californium-252 Neutron Source." J Radioanal. Chem. 50:235-247.

Volf, M. B. 1984. Chemical Approach to Glass. Glass Science and Technology \#7, Elsevier Science Publication Co., New York.

Whitehead, D., and J. E. Thomas. 1985. "Use of a Nebulizer in PyrohydroTytic Decomposition of Silicate Materials for Determination of Fluorine and Chlorine." Anal. Chem. 57:2421-2423. 


\section{APPENDIX}

PROCEDURE FOR SEPARATION OF FLUORINE AND CHLORINE BY PYROHYDROLYSIS 


\section{IITLE: $\quad 2-40.1$; FLUORIDE AND CHLORIDE SEPARATION FROM SAMPLES BY}

PYROHYDROLYSIS

\subsection{APPLICABILITY}

Water vapor is passed over a sample heated at $\geq 1000^{\circ} \mathrm{C}$. The pyrohydrolytic reaction quantitatively releases fluoride and chloride as hydrofluoric and hydrochloric acids, which volatilize and collect in a trap solution. The trap solution is analyzed for fluoride and chloride using Methods 40.2, 40.4, PNL-SP-10, or HWVP-2.

(a) Material. Uranium dioxide powder and pellets, plutonium dioxide powder, and mixed oxide powder and pellets and other refractory materials such as glasses and geologic material.

(b) Reliability. See individual fluoride and chloride methods.

(c) Interferences. None are anticipated. Care must be taken at all times to prevent contamination from extraneous fluoride and chloride, particularly chloride.

\subsection{DEFINITIONS}

None

\subsection{RESPONSIBLE STAFF}

Analyst

\subsection{PROCEDURE}

\subsection{DISCUSSION}

The use of pyrohydrolysis as a separation technique in analytical chemistry began with the separation of fluoride from uranium and thorium. 1 Pyrohydrolysis proved to be superior in speed and efficiency compared with other separation methods. Since then its use has expanded to include separation of fluoride and chloride from a variety of materials, including plutonium oxides.

In this pyrohydrolytic separation procedure, uranium and plutonium oxides are treated with water vapor at a high temperature to hydrolyze fluoride and chloride salts that may be present, producing hydrofluoric and hydrochloric acids. The pyrohydrolysis apparatus is designed such that air, argon, or nitrogen, saturated with water vapor, flows through a tube furnace containing a sample and into a basic buffer solution. The gas carries water vapor to the sample and removes the acids produced from the site of the reaction, which accomplishes separation of the halides and drives the reaction to completion. The buffer traps the acids for subsequent measurement of the fluoride and chloride. The buffer is 
used to accommodate the analytical procedure used for the fluoride measurement. ${ }^{2}$

The rate of reaction and the degree of halide recovery depend upon conditions such as temperature, flow rate of carrier gas, amount of water carried to the sample, and design of the apparatus. For example, fluoride and chloride can be lost by condensation on cooler surfaces of the apparatus if the flow rate of gas is too slow and if the distance between the exit end of the reaction tube and furnace is too long. The design of the apparatus (Figure A.1) and the conditions used in this method are similar to those used in other laboratories.3,4 A7though pyrohydrolys is occurs at lower temperatures, ${ }^{2}$ a temperature of $\geq 1000^{\circ} \mathrm{C}$ is used to help ensure the complete recovery of halides. Even then recoveries will vary, have varied as much as $20 \%$, particularly with chloride. Better recoveries are usually obtained with fluoride.

An important factor affecting recovery is the rate of the hydrolytic reaction. Certain halides such as those of the alkali metals do not hydrolyze rapidly and, therefore, an accelerator is used to promote their rapid hydrolysis. In contrast, the halides of heavy metals such as uranium and plutonium hydrolyze easily without an accelerator. When uranium and plutonium oxides are analyzed for fluoride and chloride, pyrohydrolysis is commonly done

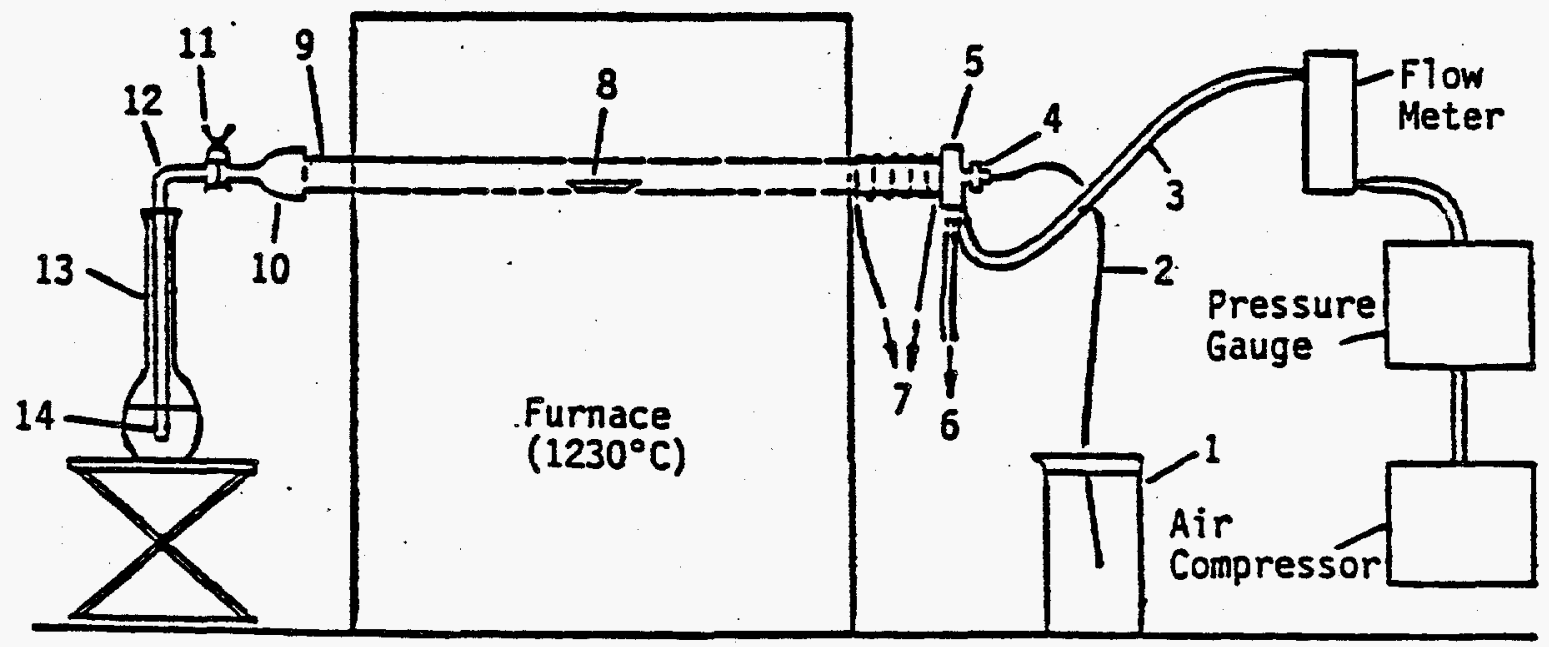

FIGURE A.1. Apparatus for Pyrohydrolysis: 1. Deionized Water; 2. Nebul izer Intake Tube $(0.6 \mathrm{~mm}$ i.d. $), ; 3$. Silicone Tubing; 4. Nebutizer; 5. PTFE Bung; 6 . Water Pipe, Open to the Air; 7 . Heating Coil $(400 \mathrm{~W}) ; 8$. Alumina Boat; 9. Alumina Combustion Tube; 10. PTFE Connector and Socket Joint, Machined from One Piece; 11. Connecting Ciips; 12. Silica Tube (15 mm i.d.), 13. Graduated Collecting Flask $(200 \mathrm{ml}) ; 14$. PTFE Bubbler 
without an accelerator. ${ }^{4}$ However, an accelerator (e.g., $\mathrm{U}_{3} \mathrm{O}_{8}$, $\mathrm{V}_{2} \mathrm{O}_{5}$ ) is always used to help ensure rapid hydrolysis and complete recovery.

Accelerators probably react to form intermediate halides that are more reactive than the starting halides. Warf, Cline, and Tevebaugh proposed that $\mathrm{U}_{3} \mathrm{O}_{8}$ promotes the hydrolysis of less reactive halides by forming uranyl halides as intermediates that readily hydrolyze to form diuranates. 1 Powell and Menis confirmed the presence of a uranyl halide and a diuranate by $x$-ray diffraction when $\mathrm{U}_{3} \mathrm{O}_{8}$ was used as an. accelerator. ${ }^{5}$

Another factor that may or may not affect recovery is the material used to fabricate the reaction tube and sample boats. In the original work with pyrohydrolysis, the reaction tube was made with platinum. ${ }^{1}$ Since then, other materials such as nickel, fused silica, and alumina have been used. Some analysts report that better fluoride recoveries are obtained if nickel is used instead of fused silica. 4 Others, however, have used fused silica successfully.2,5 Furthermore, Powe 11 and Menis reported that nickel resulted in low fluoride recoveries, 5 whereas Gahler and Porter used both nickel and fused silica successfully with chloride. 6 There is not enough evidence to rule out reaction vessel materials. Fused silica is preferred because it is inexpensive, easily obtained, and easily fabricated into desired forms.

\subsection{APPARATUS}

(a) Diamond (Plattner) or agate mortar.

(b) Pyrohydrolysis apparatus. See Figure A.1..

1. Flowmeter, capable of measuring a gas flow of at least $11 / \mathrm{min}$.

2. Water aspirator

3. Tube furnace, capable of maintaining a temperature of $\geq 1000^{\circ} \mathrm{C}$, with a heating chamber $\geq 18 \mathrm{~cm}$ long and having a diameter large enough to fit the pyrohydrolytic tube. The heating element must extend close to the outlet end of the furnace.

4. Pyrohydroltyic tube. The standard taper (inner) joints connect the pyrohydrolytic tube to the water inlet side (with respect to the flow of gas) and to the collection vessel on the outlet side. The inner joint on the outlet side has a vertical delivery tube that extends down into the collection vessel to a depth such that the tip of the delivery tube is below the surface of the buffer solution. 
It is important that the distance from the end of the tube furnace to the vertical delivery tube be as short as possible to prevent water condensation in the standard taper joint on the outlet side.

5. Sample boat

6. Collection vessel

\subsection{REAGENTS}

(a) Accelerator, $\mathrm{U}_{3} \mathrm{O}_{8}$ or $\mathrm{V}_{2} \mathrm{O}_{5}$ powdered $<1 \mu \mathrm{g} / \mathrm{g} \mathrm{Cl}$ and $\mathrm{F}$.

(b) Buffer, $0.001 \mathrm{M}$ acetic acid and $0.001 \mathrm{M}$ potassium acetate for 40.2 and 40.3 or Standard IC element described in PNL-SP-10.

(c) Compressed air, argon, or nitrogen.

(d) Distilled water, $<0.1 \mu \mathrm{g} / \mathrm{ml} \mathrm{Cl}$. and $\mathrm{F}$.

\subsection{STANDARDS}

None required.

\subsection{SAFETY}

(a) Plutonium-bearing materials are radioactive and toxic. Precautions are required to avoid the contamination of the laboratory and personnel.

(b) Observe the general laboratory safety rules.

(c) Precautions are required to avoid fires when operating a furnace in a glove box.

(d) Ceramic tops on hot plates can shatter if etched heavily by caustic. Carefully check such tops before use if they have been exposed to caustic solutions.

\subsection{QUALITY CONTROL}

\subsubsection{Calibration}

Calibration is related to the balance used. Analytical bal ances are maintained on a routine maintenance and cal ibration schedule. See Part (a) of Subsection 4.1, Vol. 1, which is under General Quality Assurance Requirements. 


\subsubsection{Control}

Control is not established directly for this method.

Controls established for the fluoride and chloride methods

(Methods 40.2, 40.3, and 40.4) apply to this method.

\subsection{ANALYSIS}

Extreme care must be taken to avoid chloride and fluoride contamination of reagents and laboratory equipment.

(a) Prepare samples, control standards, and reagent blanks as follows:

I. Crush pellets to a fine powder using the diamond (Plattner) or agate mortar.

2. Weigh 0.1 to $2 \mathrm{~g}$ of powdered sample to the nearest $0.01 \mathrm{~g}$ and mix thoroughly with $\mathrm{U}_{3} \mathrm{O}_{8}$ or $\mathrm{V}_{2} \mathrm{O}_{5}$ accelerator, using enough to cover samples.

3. Quantitatively transfer this mixture to a sample boat and spread it uniformly along the length of the boat.

4. Add same amount of accelerator to a second sample boat and spread in uniformly along the length of the boat.

This second boat, which is used for the measurement of the reagent blank, is taken through Steps (b) through ( $h$ ).

(b) Prepare the pyrohydrolysis apparatus for use as follows:

1. Turn on the tube furnace and adjust the temperature to $\geq 1000^{\circ} \mathrm{C}$.

The furnace should be turned on early to avoid delaying analysis.

2. Add distilled water to the water aspirator system, and adjust to $\approx 1-2 \mathrm{ml} / \mathrm{min}$.

3. Turn on the gas and adjust its flow to about $300-800 \mathrm{ml} / \mathrm{min}$.

(c) Open the pyrohydrolytic tube and place a collection vessel containing buffer solution into position.

(d) Insert a sample boat into the pyrohydrolytic tube and immediately close the tube. 
The sample boat must be placed in the center of the hot zone of the furnace.

(e) Let the pyrohydrolysis proceed for $\geq 15 \mathrm{~min}$.

(f) Remove the collection vessel.

(g) Open the pyrohydrolytic tube, remove the sample boat, and transfer the used sample to a waste container.

(h) Dilute the trap solution with buffer and mix thoroughiy and record final volume.

\subsection{CALCULATION}

Not applicable.

\subsection{BIBLIOGRAPHY}

1. J. C. Warf, W. D. Cline, and R. D. Tevebaugh. 1954. "Pyrohydrolysis in the Determination of Fluoride and Other Halides." Anal. Chem. 26:342.

2. C. E. Plucinski. 1968. Determination of Microgram Quantities of Fluoride in Metal Oxides, BNWL-601, Pacific Northwest Laboratory, Richland, Washington.

3. Referee Methods for the Chemical Analys is of Nuclear Fuels. USA Standard N5.7-1965, p. 37, September 1965.

4. J. E. Rein, G. M. Matlack, G. R. Waterbury, R. L. Phelps, and C. F. Metz. 1971. Methods of Chemical Analysis for FBR UraniumPlutonium Oxide Fuel and Source Material, LA-4622, Los Alamos National Laboratory, Los Alamos, New Mexico. p. 77.

5. R. H. Powell and 0. Menis. 1958. "Separation of Fluoride from Inorganic Compounds by Pyrohydrolysis." Anal. Chem. 30:1546.

6. A. R. Gahler and G. Porter. 1957. "Pyrohydrolytic Determination of Chloride in Titanium Sponge." Anal. Chem. 29:296.

Refer also to ASTM C 698, "Chemical, Mass Spectrometric, and Spectrochemical Analysis of Nuclear Grade Mixed Oxides [ $\left.(U, P u) O_{2}\right]$." 